\title{
Desigualdade de Renda e Demanda por Redistribuição Caminham Juntas na América Latina no Período 1997-2015
}

\author{
Yasmín Salazar Méndez ${ }^{1}$ \\ Fábio Domingues Waltenberg ${ }^{2}$ \\ ${ }^{1}$ Escuela Politécnica Nacional, Quito, Equador. E-mail: yasmin.salazar@epn.edu.ec. \\ ${ }^{2}$ Universidade Federal Fluminense (UFF), Niterói, RJ, Brasil. E-mail: \\ waltenberg@economia.uff.br.
}

\section{INTRODUÇÃO}

D or que há mais redistribuição de renda em alguns países do que em 1 outros? Certamente preferências individuais por redistribuição são determinantes. Não obstante, os fatores que moldam tais preferências e os mecanismos pelos quais elas afetam a agenda político-econômica dos países constituem um quebra-cabeça composto por peças micro e macroeconômicas. A maior parte das análises disponíveis na literatura tem contribuído para o entendimento das diferenças de preferências e atitudes redistributivas entre cidadãos da Europa e dos Estados Unidos. Menos farta é a literatura sobre os latino-americanos.

Compreender a importância relativa das diferentes motivações para mais ou menos apoio à redistribuição nos países latino-americanos é fundamental para o desenho de políticas redistributivas e de sistemas de tributação que se mostrem, simultaneamente, eficazes em seus objetivos, e robustos - por exemplo, às alternâncias políticas. Estudar o assunto também serve a uma melhor compreensão do surgimento de conflitos sociais ou da posição (in)tolerante dos habitantes de um país frente a situações de desigualdade social.

Em obra influente baseada em premissas simples, como a primazia do autointeresse, Meltzer e Richard (1981) sugeriram que as preferências redistributivas seriam afetadas pela situação econômica individual e DADOS - Revista de Ciências Sociais, Rio de Janeiro, vol. 61, n-4, 2018, pp. 341 a 384. 
pela distribuição de renda vigente na sociedade. Em sua visão, o poder decisório repousaria sobre o eleitor mediano, que seria favorável à redistribuição sempre que tivesse uma renda menor do que a média, de modo que, em países com alta desigualdade, haveria apoio à redistribuição. Abordagens baseadas nesse quadro analítico, contudo, passaram a ser desafiadas em face de resultados contraditórios.

Trabalhos posteriores sofisticaram a análise, passando a considerar que, ao definir seu nível de demanda por redistribuição, os indivíduos levariam em conta aspectos que vão além do pecuniário. Por exemplo, expectativas de mobilidade social teriam sua importância. Indivíduos com baixa renda no presente poderiam ser contrários a políticas redistributivas, sempre que tivessem uma expectativa de melhorar sua situação econômica no futuro (Piketty, 1995; Bénabou e Ok, 2001). Aspectos culturais, religiosos e macroeconômicos também passaram a ser considerados (Alesina e Giuliano, 2011).

Em um nível agregado, a desigualdade de renda tem sido uma das variáveis de maior interesse. Alguns estudos confirmam a previsão de Meltzer e Richard, ao encontrar efeito positivo da desigualdade sobre a demanda por redistribuição em países europeus (Jaeger, 2013; Olivera, 2014; Pittau, Massari e Zelli, 2012). Mais recentemente, autores como Karabarbounis (2011) e Milanovic $(2000,2010)$ confirmaram as previsões do modelo tradicional, ainda que apenas de forma parcial. Porém, a controvérsia se manteve, por meio de novos trabalhos com os mesmos dados usados no artigo pioneiro, de modelos teóricos alternativos e de evidências empíricas produzidas nos anos seguintes, que não corroboraram todas as previsões (Tullock, 1983; Gouveia e Masia, 1998; Moene e Wallerstein, 2003; Kenworthy e McCall, 2008).

Sabe-se de longa data que a América Latina é a região mais desigual do mundo em termos de distribuição de renda, o que, por si só, já a torna um interessante objeto de estudo sobre a relação entre distribuição de renda e apoio à redistribuição.

Também se sabe que, no início do século XXI, muitos países latinoamericanos implementaram políticas que, se não alteraram estruturalmente a economia e a sociedade, ao menos suavizaram algumas manifestações da desigualdade. ${ }^{1}$ Uma eventual continuidade ou intensificação do processo dependeria de um concurso de circunstâncias, entre as quais uma conjuntura econômica internacional adequada, uma cor- 
Desigualdade de Renda e Demanda por Redistribuição Caminham Juntas...

relação favorável de forças políticas, a presença de quadros capazes de diagnosticar entraves e formular políticas redistributivas.

Além dessas condicionantes, as aspirações da população precisam ser consideradas de alguma forma, de modo que se faz necessário indagar o que a população almeja em termos distributivos. Será que os latino-americanos naturalizaram a desigualdade porque sempre esteve presente na região, ou será que as (pequenas) mudanças recentes alteraram preferências e atitudes frente à redistribuição? Todas as camadas socioeconômicas apoiam políticas redistributivas, mesmo as que saíram perdendo, em termos relativos? Como comparar os padrões já relativamente bem estabelecidos de preferências redistributivas de europeus e estadunidenses aos de latino-americanos?

Fenômeno coincidente com a redução da desigualdade, e a ela relacionado, foi o crescimento da chamada "nova classe média", que passa de 103 milhões a 152 milhões de pessoas entre 2003 e $2009 .{ }^{2}$ Se antes os pobres eram duas vezes e meia mais numerosos que a classe média, agora apresentam-se em proporção igual (Ferreira et alli, 2013). Este segmento da população pode ter papel político decisivo, garantindo estabilidade política e apoio - ou não - às estruturas de tributação e de gasto social vigentes (Cornia, 2013). Na linguagem da literatura de demanda por redistribuição: estaria nessa "nova classe média" o eleitor mediano?

Não nos parece que haja respostas dadas de antemão às questões arroladas nos parágrafos acima. Parte da explicação para isso é que, até o momento, poucos estudos tomaram os países latino-americanos como objeto de análise, entre os quais se incluem Gaviria (2007), Dion e Birchfield (2010), e Silva e Figueiredo (2013). Tais autores trabalharam com periodizações, metodologias e enfoques um pouco diferentes dos adotados neste trabalho.

O principal estudo a focar na relação entre demanda por redistribuição e desigualdade na América Latina é Cramer e Kaufman (2011), que levaram em conta a estrutura multinível de dados empilhados dos anos 1997, 2001 e 2002, obtendo como resultado um discreto efeito positivo da desigualdade na demanda por redistribuição. Sugerem também que, contraintuitivamente, pessoas de baixa renda não seriam os principais protagonistas a reivindicar igualdade social.

Este artigo contribui à literatura, em primeiro lugar, porque investiga o papel da desigualdade de renda nas preferências por redistribuição na

DADOS - Revista de Ciências Sociais, Rio de Janeiro, vol. 61, nº 4, 2018 
América Latina, com controles para uma grande bateria de variáveis individuais (microdados do Latinobarômetro) e dados macroeconômicos (Banco Mundial e Standardized World Income Inequality Database). Em segundo lugar, porque, de modo inovador, estimou-se um modelo multinível híbrido (efeitos interpaíses e intrapaíses) sobre um pseudopainel, o que permite levar em conta variações temporais e por país, e eliminar parte da heterogeneidade não observada. A terceira contribuição, de grande importância, repousa sobre o recorte temporal adotado. O período analisado não só é relativamente longo (1997-2015), como também presenciou oscilação da desigualdade de renda na região, em intensidade e duração distintas nos diferentes países - variabilidade que é importante para fins de estimação.

Como principais resultados dos exercícios econométricos reportados aqui, destaque-se primeiro a observação de uma relação positiva entre desigualdade e probabilidade de apoio a políticas redistributivas, corroborando a previsão clássica do modelo MR, inclusive após a inclusão de uma série de controles individuais e de variáveis agregadas de crescimento, riqueza e gasto social, e por meio de uma técnica de estimação relativamente sofisticada. A insatisfação com a distribuição de renda é mais intensa entre pobres e a classe média, mas não tanto entre os "vulneráveis", categoria mais próxima da "nova classe média"; não temos elementos para determinar claramente o papel do eleitor mediano nas perspectivas de mudanças futuras.

A esta seção introdutória, segue-se uma revisão da literatura de desigualdade e preferências por redistribuição, após o que se apresentam os dados e a metodologia. Por fim, figuram as seções de apresentação e discussão de resultados, e as conclusões do estudo.

\section{DESIGUALDADE E PREFERÊNCIAS POR REDISTRIBUIÇÃO}

Meltzer e Richard (1981) propõem um modelo teórico (doravante: modelo MR) para explicar as preferências por redistribuição, cuja implicação principal é que a renda individual afetaria negativamente a demanda por redistribuição. Em nível agregado, considerando como desigualdade a distância entre renda média e renda do eleitor decisivo, quanto mais desigual fosse um país, maior seria o apoio à redistribuição.

O modelo parte de premissas à primeira vista razoáveis e desemboca em conclusões lógicas - é natural supor que os mais pobres apoiem po- 
Desigualdade de Renda e Demanda por Redistribuição Caminham Juntas...

líticas redistributivas e os ricos sejam contrários, e que sociedades desiguais almejem uma distribuição mais igualitária. O artigo encontrou suporte às previsões teóricas ao analisar os Estados Unidos no período 1936-1972.

Novos trabalhos com os mesmos dados, modelos teóricos alternativos e evidências empíricas produzidas nos anos seguintes pouco a pouco puseram em xeque as previsões do modelo. Tullock (1983), por exemplo, questiona o resultado obtido, ao mostrar que a relação entre a renda do eleitor mediano e a renda média se manteve constante no período analisado, mas não o tamanho do governo americano. Karabarbounis (2011) alerta que grupos abastados podem influenciar a agenda político-econômica em prol de menos tributação e redistribuição, no equilíbrio conhecido como one dollar, one vote. Milanovic $(2000,2010)$ corrobora apenas parcialmente o modelo MR - embora encontre indícios de que países mais desiguais redistribuem mais, não necessariamente se verifica o poder de decisão do eleitor mediano. Não chegaram a encontrar efeito da desigualdade nas preferências por redistribuição autores como Persson e Tabellini (1994), Gouveia e Masia (1998), Kenworthy e McCall (2008), Moene e Wallerstein (2003). ${ }^{3}$

Resultados contraditórios deram origem ao chamado "paradoxo da redistribuição", que sintetiza a situação em que há pouco apoio à redistribuição em países muito desiguais, e muito apoio nos quais a desigualdade é menor - cujo exemplo clássico é o contraste entre Estados Unidos e Europa (Alesina e Giuliano, 2011; Karabarbounis, 2011).

O modelo MR parecia estar, no mínimo, incompleto. Novos fatores foram incorporados, mas os resultados também foram mistos. Bredemeier (2014) levou em conta a informação imperfeita, considerando que a votação depende da percepção que tem o eleitor mediano sobre sua posição econômica; em tal contexto, pessoas pobres com renda crescente seriam menos favoráveis a redistribuir. Gouveia e Masia (1998) introduziram mobilidade, supondo que mudanças na política fiscal e no estado de bem-estar poderiam gerar ondas migratórias, com pessoas abandonando um território por causa dos tributos e outras sendo atraídas por benefícios sociais. De forma geral, os resultados lançaram mais dúvidas sobre a validade do modelo MR.

A esta altura, cabe sintetizar vantagens e limitações do modelo MR. Por um lado, são indiscutíveis a parcimônia e a possibilidade que oferece de fazer generalizações e previsões precisas sobre o comportamento relacionado com políticas redistributivas. Por outro lado, o mo- 
delo vale-se, de forma acrítica, de pressupostos do mainstream da teoria econômica, copiosamente contestados em décadas recentes, tais como: individualismo e autointeresse sem nuances, racionalidade perfeita, preferências exógenas e estruturas de decisão sujeitas a restrições unicamente orçamentárias. Ademais, não há incerteza, a interação social inexiste, e se faz abstração completa dos ambientes econômico, social, legal e cultural.

Como já dito, no modelo MR, nos países com altos níveis de desigualdade, a demanda por redistribuição seria maior. Contudo, pode-se supor que a segregação social gerada como consequência de uma desigualdade estrutural tenha um papel definidor do comportamento de diferentes grupos sociais. Lupu e Pontusson (2011) argumentam que a estrutura da desigualdade, aspecto pouco considerado na literatura, explicaria diferentes posturas redistributivas da classe média. Se a distância entre a classe média e os pobres fosse grande, a classe média seria menos favorável à redistribuição, pelo fato de seus membros se sentirem mais identificados com os ricos. O contrário aconteceria no caso de haver mais proximidade entre a classe média e os pobres. Desta forma, presume-se que ocorrerá variação entre países, e num mesmo país ao longo do tempo, da posição da classe média frente a políticas redistributivas, propensa a uma atitude menos estável se comparada com as posições de ricos e pobres. Em sociedades segregadas, inclusive com desdobramentos na desigualdade de participação política, pobres teriam menos voz e menos oportunidades de serem beneficiados com políticas redistributivas, mesmo por partidos de esquerda (McCarty e Pontunsson, 2009).

Na democracia, com a extensão dos direitos políticos aos pobres, esperar-se-ia que se implementassem políticas redistributivas robustas, com consequente queda da desigualdade. Todavia, evidências contraditórias sugerem que os efeitos da democracia na construção de sociedades mais igualitárias não são tão imediatos e lineares. Acemoglu, Johnson e Robinson (2013), por exemplo, procuram compreender por que a análise tradicional que vincula positivamente democracia com redução da desigualdade pode falhar. Primeiro, pode-se tratar de uma democracia "limitada", na qual grupos de interesse pressionariam a política redistributiva norteados por seu próprio interesse. Segundo, os processos de democratização não se traduziriam necessariamente em mais igualdade, pois os setores excluídos em períodos não democráticos competiriam desigualmente com as elites para lograr um espaço em áreas antes restritas e destinadas aos grupos privilegiados, ge- 
Desigualdade de Renda e Demanda por Redistribuição Caminham Juntas...

rando mais desigualdade. Terceiro, recorrem à Director's Law mencionada por Stigler (1970), segundo a qual a classe média domina os processos políticos e tem o controle da tomada de boa parte das decisões na sociedade. Nessa visão, o poder que outorga a democracia à classe média poderia ser um limitante à redistribuição se essa classe média não se mostrasse decidida a apoiar a causa dos mais pobres.

A redistribuição em determinado país também dependerá das condições econômicas gerais. Por exemplo, o crescimento do produto interno bruto poderia ter efeito negativo sobre a demanda por redistribuição, porque, ao se sentirem menos expostos a riscos econômicos, os indivíduos reclamariam menos proteção governamental (Dion e Birchfield, 2010; Cramer e Kaufman, 2011; Jaeger, 2013; e Haggard, Kaufman e Long, 2013). Já da riqueza, comumente medida pelo PIB per capita, mostraria efeito positivo sobre a demanda por redistribuição, mas somente até o ponto em que a maioria da população atingisse certo patamar de padrão de vida, além do qual se observaria um efeito de saturação no qual as pessoas não apoiariam mais com tanto empenho a redistribuição (Haller et alli, 1989).

Outras variáveis agregadas de interesse são o nível de desemprego e o gasto social. Da primeira se esperaria um efeito positivo: em épocas de alta no desemprego, a população reivindicaria mais proteção estatal para enfrentar riscos sociais (Dallinger, 2010). Quanto ao gasto social, poderia haver efeitos contraditórios, e de fato a evidência é mista. Por exemplo, países com welfare state muito desenvolvido, como os países nórdicos, exibem baixo apoio à redistribuição e baixa desigualdade simultaneamente (Olivera, 2014). Fazendo referência também aos países nórdicos, Finseraas (2009) argumenta que, se a hipótese de correlação positiva entre gasto social e apoio à redistribuição fosse verdadeira, não se deveria esperar uma relação positiva entre desigualdade e demanda por redistribuição. Schmidt (2016) também reporta um resultado contraditório ao mostrar uma relação inversa entre o nível de gasto social e a demanda por redistribuição na Europa.

\section{DADOS E METODOLOGIA}

\section{Fontes dos Dados}

Os dados foram obtidos em três fontes diferentes: Latinobarômetro, Standardized World Income Inequality Database (SWIID) e Banco Mundial (BM).

DADOS - Revista de Ciências Sociais, Rio de Janeiro, vol. 61, nº 4, 2018 
Os dados individuais provêm do Latinobarômetro, survey que é realizado sob responsabilidade da Corporação Latinobarômetro. As entrevistas são aplicadas a maiores de 18 anos das áreas urbana e rural, com exceção de Brasil e Nicarágua, países nos quais a idade mínima é 16 anos.

Apesar de não ser uma pesquisa especifica para temas de igualdade e redistribuição, apresenta algumas características desejáveis para realizar este estudo. A primeira é que vem sendo realizado anualmente desde 1995 em 18 países da América Latina. ${ }^{4}$ Outro traço a destacar é que ela capta a opinião pública em assuntos relacionados a democracia, economia, política, religião, muitos dos quais servem aos propósitos deste estudo. A comparabilidade temporal é outra vantagem, visto que algumas perguntas variam de ano a ano, não obstante, há questões que têm sido mantidas idênticas ou muito parecidas ao longo das diferentes edições da coleta de dados.

Uma deficiência do Latinobarômetro - comum a muitas outras bases de dados, em virtude da conhecida dificuldade de coletá-las (Montgomery et alli, 2000; Filmer e Pritcher, 2001) - é a ausência de informações sobre renda individual ou domiciliar, deficiência que é atenuada pela existência de dados sobre a situação econômica dos entrevistados.

Face a tantas vantagens, compreende-se por que tantos outros estudos sobre preferências de latino-americanos por redistribuição tenham recorrido ao Latinobarômetro também (Gaviria, 2007; Dion e Birchfield, 2010; Cramer e Kaufman, 2011; Silva e Figueiredo, 2013). Nenhum deles, porém, teve abrangência temporal tão longa quanto este trabalho, que usou nove rodadas para análise: 1997, 2001, 2002, 2007, 2009, 2010, 2011, 2013 e 2015. No Apêndice A, apresenta-se o número de observações por país e por ano.

Da Standardized World Income Inequality Database (SWIID), discutida em Solt (2009), foi tomada a medida de desigualdade, a saber: índice de Gini. Usaram dados do SWIID em seus estudos de preferências por redistribuição autores como Haggard, Kaufman e Long (2013), Oliveira (2013) e Pittau, Massari e Zelli (2012). Da base de dados do Banco Mundial, foram extraídos o PIB per capita e o crescimento do PIB.

\section{Desafios Metodológicos e a Motivação para se Combinar Multinível Híbrido e Pseudopainel}

Algumas limitações metodológicas afetam recorrentemente os estudos nessa área, entre os quais: (i) variáveis omitidas; (ii) simultaneida- 
Desigualdade de Renda e Demanda por Redistribuição Caminham Juntas...

de: pois pessoas que moram em países mais desiguais poderiam demandar maiores níveis de redistribuição, e, sistemas de redistribuição avançados também poderiam moldar preferências individuais por redistribuição generosas; (iii) ausência de controle da heterogeneidade não observada entre os diferentes grupos de análise.

Análises que envolvem países como unidade de análise podem enfrentar o problema de clustering. Moulton (1986) argumenta que, ao se usar, por exemplo, uma técnica de mínimos quadrados ordinários, se estaria violando o pressuposto de independência das observações e, consequentemente, obtendo-se estimadores enviesados. Entre as possíveis soluções para o clustering está o cálculo do erro padrão robusto com clusters, considerado uma generalização do estimador de White para o caso de dados com estrutura de clusters (Cameron, Gelbach e Miller, 2008). Apesar de ser um método bastante utilizado por economistas, tem como requisito um grande número de grupos, e a violação desta condição também pode gerar estimadores enviesados (Angrist e Pischke, 2009; Cameron, Gelbach e Miller, 2008).

Os modelos multinível, também conhecidos como modelos mistos, constituem-se em outra opção para trabalhar com clusters; não obstante, sua aplicação pode ser problemática se não houver um grande número de grupos. Em geral, recomenda-se que se trabalhe com ao menos 50 grupos, para garantir uma distribuição aleatória do termo de erro nos distintos níveis de análise, e porque um número diminuto de grupos reduz os graus de liberdade e tolhe a potência dos testes estatísticos (Maas e Hox, 2005; Möhring, 2012; Schmidt, 2016). Adicionalmente, Schmidt (ibidem) mostra que a omissão de variáveis pode enviesar estimadores obtidos mediante modelos multinível.

Uma alternativa para mitigar alguns dos problemas mencionados consistiria em se usar variáveis instrumentais. Contudo, Tóth e Keller (2011) expressam uma dificuldade recorrente, que é a de se encontrar uma variável adequada.

Apesar de também sofrerem de algumas limitações - tais como fricção, observações faltantes e menor número de observações se comparados com dados em corte transversal - painéis de dados permitem controlar a heterogeneidade individual, mitigar efeitos não observados e variáveis omitidas, e costumam proporcionar variabilidade e pouca colinearidade, razões pelas quais são considerados o melhor recurso para capturar mudanças comportamentais individuais no tempo e presu- 
mir um efeito causal (Andreß, Golsch e Schmidt, 2013; Baltagi, 2005; Hsiao, 1986). A dificuldade é que nem sempre há dados deste tipo e, quando os há, em geral abrangem apenas países desenvolvidos (Alesina e Angeletos, 2005 e Alesina e La Ferrara, 2005).

Para enfrentar as limitações metodológicas, bem como a escassa disponibilidade de dados em painel, alguns autores incursionaram na construção de pseudopainéis (Schmidt, 2016; Olivera, 2014; Jaeger, 2013). Baseado em Fairbrother (2011), que propusera um modelo multinível com dados empilhados, Schmdit (2016) sugere uma estimação híbrida que consiste em estimar efeitos interpaíses (aleatórios) e intrapaíses (fixos) num pseudopainel.

Pelo exposto anteriormente, e considerando a disponibilidade de dados para a América Latina, neste artigo adotou-se a estratégia empírica de Schmidt (2016), ou seja, uma estimação multinível com pseudopainel com efeitos fixos e aleatórios. A seguir, descreve-se a construção do pseudopainel e a especificação multinível.

\section{A Construção do Pseudopainel}

Deaton (1985) propôs construir painéis sintéticos a partir de dados de corte transversal repetidos, como alternativa à falta de painéis genuínos. Os chamados pseudopainéis são construídos definindo coortes $C$, que são grupos de indivíduos que compartilham características individuais similares, invariantes no tempo tais como: ano de nascimento, sexo, cor, país de nascimento.

Parte-se de um modelo de uma especificação para dados em painel que considera um modelo com efeitos tanto individuais quanto temporais:

$$
\begin{gathered}
y_{i t}=\alpha+\beta x_{i t}^{\prime}+\gamma Z_{i t}^{\prime}+\mu_{i t} \\
\mu_{i t}=\theta_{i}+v_{i t}
\end{gathered}
$$

onde $\mathrm{i}\left(\mathrm{i}=1, \ldots, \mathrm{I}_{\mathrm{t}}\right)$ representa os indivíduos no ano te $\mathrm{t}=(1, \ldots, \mathrm{T})$ denota $\mathrm{o}$ ano, $\mathrm{X}_{\mathrm{it}}$ é um k-vetor de variáveis explicativas individuais e $\alpha$ é um k-vetor de parâmetros, $Z_{i t}$ contém as medidas de desigualdade e de riqueza, valores que são iguais para indivíduos do mesmo país e ano, e $\mu_{i t}$ tem efeitos fixos individuais e temporais e o $v_{i t}$ é o erro.

Este modelo, conhecido como two-way effects, é uma extensão do modelo de efeitos individuais, que permite ao intercepto variar tanto no nível individual como temporal; todavia, quando o número de períodos 
Desigualdade de Renda e Demanda por Redistribuição Caminham Juntas...

é pequeno, é comum considerar $\gamma_{t}$ como efeitos fixos (Cameron e Trivedi, 2009), e a Equação (1) transforma-se num modelo one-way.

Realizando a transformação de Deaton (1985) na Equação (1) tem-se:

$$
\bar{y}_{c t}=\bar{\theta}_{c t}+\beta \bar{x}_{c t}^{\prime}+\gamma \bar{z}_{c t}^{\prime}+\bar{v}_{c t} \quad c=1, \ldots, C t=1, \ldots, T
$$

onde $\bar{y}_{c t}, \bar{x}_{c t}^{\prime}, \bar{z}_{c t}^{\prime}$ são a média das observações de todos os indivíduos pertencentes à coorte $\mathrm{C}$ no tempo $\mathrm{t}$ de cada uma das variáveis.

Como o modelo da Equação 1 inclui efeitos fixos individuais e temporais, o modelo de coortes (3) também contém efeitos fixos das coortes e agora $\bar{\alpha}_{\mathrm{ct}}$ varia no tempo e, em geral, está correlacionada com as outras variáveis explicativas (Deaton, ibidem). A estimação sob esta condição poderia causar um problema de identificação a menos que $\bar{\theta}_{\mathrm{ct}}=\bar{\theta}_{\mathrm{c}}, \mathrm{o}$ que é plausível no caso em que cada coorte seja formada por um grande número de indivíduos, de forma que $\bar{\theta}_{\text {ct }}$ seja uma boa aproximação de $\bar{\theta}_{\mathrm{c}}$ (Deaton, ibidem; Verbeek, 2008). Não obstante, também é possível usar em (3) um estimador within baseado numa transformação das coortes (Baltagi, 1995):

$$
\bar{y}_{c t}=\bar{y}_{c t}-\bar{y}_{c}
$$

onde $y_{c t}^{*} x_{c t}^{*} z_{c t}^{*}$ são as médias da população das coortes, as quais não são observáveis e $\theta_{c}$ e $\gamma_{t}$ são efeitos fixos da população que, assume-se, são constantes no tempo.

Não existe um consenso na literatura sobre o número de indivíduos por coorte que permitiria prevenir o problema de erros de medida nas variáveis. Verbeek e Nijman (1992) mostram que os erros nas variáveis podem ser ignorados quando o número de observações por coorte $n_{c}=N / C$ é grande (100, 200 indivíduos), contanto que o pseudopainel apresente suficiente variação temporal. Com $\mathrm{n}_{\mathrm{c}}$ grande, os autores mostram que o estimador within e o proposto por Deaton (1985) são assintoticamente idênticos, daí que na literatura de pseudopainéis a preocupação não está relacionada com os erros de medida, e sim com a estrutura de $\mathrm{n}_{\mathrm{c}}$. Por exemplo, com uma aplicação à oferta de trabalho feminina, Devereux (2007) mostra que, apesar de ter 10.000 observações por coorte, o viés se mantém. A definição do número de unidades por coorte se complica dado que existe um trade-off: se o número de coortes $C$ é grande, o pseudopainel tem um grande número de observações, porém um $n_{c}$ pequeno, que pode trazer estimadores não precisos.

DADOS - Revista de Ciências Sociais, Rio de Janeiro, vol. 61, nº 4, 2018 
Um pseudopainel com poucas coortes $C$ e mais observações por coorte, traz poucas observações, embora sejam mais precisas (Baltagi, 2005).

\section{Desenho das Coortes}

Para a construção das coortes foram considerados os seguintes aspectos: (i) estabilidade das coortes; (ii) número de coortes e tamanho do N.

Para garantir a estabilidade das coortes, é desejável usar informações invariantes no tempo, contudo, simultaneamente também se deve observar a inclusão de variáveis que incrementem a heterogeneidade dos grupos. As variáveis consideradas neste estudo são: ano de nascimento, sexo e país de residência.

- Ano de nascimento: esta variável é perfeitamente invariante no tempo, e estudos prévios sugerem uma estreita relação entre idade e atitudes redistributivas. Esta variável também permite incorporar o efeito geracional. Ryder (1965) manifesta que as coortes de nascimento permitem uma leitura que combina um componente histórico e outro inovador, presentes em todas as sociedades. O primeiro preserva o legado cultural das gerações passadas, garantindo a continuidade, e o segundo é responsável pelas transformações que se sucedem naturalmente nas sociedades pelo efeito da educação, das experiências pessoais e do processo de socialização.

- Sexo: variável também invariante no tempo; estudos encontram efeito positivo significativo das mulheres nas preferências por redistribuição.

- País de residência: esta variável poderia apresentar uma limitação devido ao fluxo migratório da região, fenômeno particularmente presente nos países da América Central; não obstante, considerar este critério para a construção das coortes ajuda a preservar a heterogeneidade que pode existir entre os habitantes dos diferentes países latino-americanos. Adicionalmente, estudos prévios indicam diferenças da atitude redistributiva entre habitantes de países diferentes.

Um número maior de coortes incrementa o número de observações, ponto importante para obter estimadores eficientes, enquanto incrementos no tamanho das coortes que, por sua vez também implicam um menor número de coortes, reduzem os erros de mensuração.

Foram criados três pseudopainéis (PS1, PS2, PS3) com diferentes números de coortes. O primeiro pseudopainel tem coortes de ano de nas- 
Desigualdade de Renda e Demanda por Redistribuição Caminham Juntas...

cimento com uma distância de sete anos, o segundo considera uma distância de 10 anos, e o último não considera o sexo como critério de coorte utilizando uma distância de 10 anos entre os anos de nascimento. Assim, o número máximo de observações é: 2.268 , 3.240 e 1.620, respectivamente.

As propriedades dos pseudopainéis podem variar dependendo do tamanho das coortes, do número de períodos disponíveis, das variáveis consideradas para a construção das coortes, contudo, de forma geral, os critérios para a avaliação podem considerar cenários com diferentes relações entre a variância inter e intragrupos, e diferentes considerações do número de coortes e observações com o objetivo de analisar o trade-off entre estes dois critérios. Para a seleção do melhor estimador, utilizou-se o critério comumente utilizado na estatística clássica, que é a Raiz do Erro Quadrático Médio (REQM), medida que leva em conta simultaneamente o viés de um estimador e sua eficiência relativa (entre os estimadores enviesados, aquele com menor variância).

Para avaliar o pseudopainel que gera os estimadores mais eficientes e com menos viés, realizou-se uma simulação de Monte Carlo, a fim de investigar as propriedades econométricas dos estimadores. ${ }^{5}$

A partir dos resultados (1.000 réplicas em cada caso, ver Apêndice B), com relação à variância intergrupos $\left(\sigma_{B}^{2}\right)$ e intragrupos $\left(\sigma_{W}^{2}\right)$, como esperado, nos modelos nos quais se considera $\left(\sigma_{B}^{2}\right)>\left(\sigma_{W}^{2}\right)$, os desvios padrão dos estimadores FE são maiores, situação que se acentua nos pseudopainéis com menor número de coortes. A obtenção de estimadores FE sob estas condições tem sido alvo de controvérsia. O estimador "fixed-effects vector decomposition" (fevd) proposto por Plümper e Troeger $(2011,2007)$, que permitiria a obtenção de estimadores eficientes em painéis com variáveis com baixa variância intragrupos - denominadas como "rarely changing variables" -, assim como de variáveis que não variam no tempo, tem recebido algumas críticas que sugerem cautela no uso do estimador (Greene, 2011; Breusch et alli, 2011; Breusch et alli, 2011b).

Acerca do número de coortes, grupos e períodos, os modelos M5 e M6, que correspondem ao PS2, o qual considera o maior número de coortes, mostram menor REQM, o que significa que é preferível diminuir o número de observações por coorte para aumentar o número de coortes.

DADOS - Revista de Ciências Sociais, Rio de Janeiro, vol. 61, nº 4, 2018 
Dado o desempenho mostrado no experimento de Monte Carlo, escolheu-se o PS2. A composição do pseudopainel aparece na Tabela 1:

Tabela 1

Observações por Coorte

\begin{tabular}{lrrrrrrrrrr}
\hline Coorte & $\mathbf{1 9 9 7}$ & $\mathbf{2 0 0 1}$ & $\mathbf{2 0 0 2}$ & $\mathbf{2 0 0 7}$ & $\mathbf{2 0 0 9}$ & $\mathbf{2 0 1 0}$ & $\mathbf{2 0 1 1}$ & $\mathbf{2 0 1 3}$ & $\mathbf{2 0 1 5}$ & Total \\
\hline $1898-1907$ & 0 & 0 & 0 & 0 & 0 & 0 & 0 & 0 & 0 & 0 \\
$1908-1917$ & 0 & 0 & 0 & 0 & 0 & 0 & 0 & 0 & 0 & 0 \\
$1918-1927$ & 4 & 5 & 1 & 0 & 0 & 0 & 0 & 0 & 0 & 10 \\
$1928-1937$ & 13 & 13 & 10 & 9 & 8 & 6 & 1 & 1 & 0 & 61 \\
$1938-1947$ & 30 & 34 & 31 & 34 & 33 & 31 & 36 & 30 & 25 & 284 \\
$1948-1957$ & 33 & 34 & 34 & 36 & 36 & 36 & 36 & 36 & 36 & 317 \\
$1958-1967$ & 34 & 34 & 34 & 36 & 36 & 36 & 36 & 36 & 36 & 318 \\
$1968-1977$ & 34 & 34 & 34 & 36 & 36 & 36 & 36 & 36 & 36 & 318 \\
$1978-1987$ & 8 & 34 & 34 & 36 & 36 & 36 & 36 & 36 & 36 & 292 \\
$1988-1997$ & 0 & 0 & 0 & 29 & 36 & 36 & 36 & 36 & 36 & 209 \\
\hline Total & 156 & 188 & 178 & 216 & 221 & 217 & 217 & 211 & 205 & 1809 \\
\hline
\end{tabular}

Fonte: Latinobarômetro, 1997, 2001, 2002, 2007, 2009, 2010, 2011, 2013, 2015. Elaboração própria.

O pseudopainel obtido não é balanceado e apresenta períodos de tempo desiguais. Esta última característica, no caso de modelos não dinâmicos, não impede que se apliquem as mesmas ferramentas usadas em pseudopainéis igualmente distribuídos no espaço. Já a outra característica mencionada é própria estrutura dos dados, pois cada coorte tem um número de indivíduos diferente e que varia no tempo (Baltagi e Song, 2006).

As coortes mais antigas apresentam poucas observações (ou nenhuma), pois coortes com menos de 25 observações foram excluídas. Com respeito a variância, no Apêndice $C$ se apresentam a variância intergrupos (diferenças entre a média grupal e a média total) e a variância intragrupos (diferenças entre cada observação e a média do seu grupo). Todas as variáveis mostram variâncias intergrupos maiores do que as variância intragrupos. As variáveis de estado civil e emprego mostram suficiente variação entre e intragrupos. As variáveis de classe socioeconômica apresentam baixa variação intragrupos, pois pessoas pertencentes a um mesmo quintil têm uma caracterização bastante similar.

Uma vez construído o pseudopainel, estimaram-se modelos multinível híbridos, com observações correspondentes a múltiplos períodos, 
Desigualdade de Renda e Demanda por Redistribuição Caminham Juntas...

conforme proposto por Fairbrother (2011). Esse tipo de estrutura contém observações repetidas - por país, por ano e por coorte - e permite decompor os efeitos em todos os níveis, ou seja, interpaíses $\left(Z_{2 j t}\right)$ e intrapaíses $\left(x_{j i t}\right)$. A partir da especificação básica multinível obtém-se a seguinte expressão híbrida (Fairbrother, 2014):

$$
y_{j t i}=\theta_{0}+\beta_{1} x_{j t i}+\gamma^{\text {intra }}\left(Z_{j t}-\bar{Z}_{j}\right)+\gamma_{2}^{\text {inter }} \bar{Z}_{j}+u_{1 i}+u_{2 j i}+e_{t j i}
$$

onde há três níveis de variação: i indivíduos i, aninhados em t países-tempo, e j países. $u_{1 i}, u_{2 j i}$ são os efeitos aleatórios que capturam heterogeneidade não observada ao nível país e de indivíduos, respectivamente. $x_{j i t}$ contém as variáveis ao nível individual, $z_{j t}$ inclui as variáveis ao nível agregado. A inclusão dos termos: $\bar{z}_{j,}\left(\bar{z}_{j t}-\bar{z}_{j}\right)$ permite a estimação dos efeitos inter e intra (Fairbrother, 2014).

\section{Variáveis}

\section{Variável Dependente}

De modo similar ao que se vê em trabalhos anteriores, se extrai o apoio à redistribuição dos entrevistados de uma questão indireta, tal como a escolhida neste artigo: "Quão justa você crê que é a distribuição de renda no país: muito injusta (4), injusta (3), justa (2), muito injusta (1), não sabe?". Disponível no Latinobarômetro em todos os anos analisados, esta pergunta permite captar informação sobre a percepção dos entrevistados em relação ao aspecto distributivo. Foi usada como variável dependente em outros estudos de preferências por redistribuição para a América Latina (Silva e Figueiredo, 2013; Cramer e Kaufman, 2011), o que não nos isenta de apontar algumas de suas limitações.

Da forma como está formulada a pergunta, pode-se esperar a expressão de um alto grau de descontentamento com a distribuição, sem que isto necessariamente represente um forte apoio a políticas redistributivas. Por exemplo, visto que a redistribuição pode ser realizada por diversos canais, alguns mais visíveis e controvertidos, como programas de transferência de renda, e outros menos palpáveis, como o seguro-desemprego, algumas pessoas poderiam considerar injusta a distribuição de renda e apoiar algumas formas de redistribuição, mas não outras (Sefton, 2005).

Ervasti (2012) sugere que questões que abordam aspectos da redistribuição de forma positiva - usando termos como equidade, bem-estar,

DADOS - Revista de Ciências Sociais, Rio de Janeiro, vol. 61, nº 4, 2018 
justiça - poderiam carregar o risco de sobre-estimar o apoio à redistribuição, de modo que sua recomendação é incluir perguntas que levem em conta também aspectos negativos da redistribuição - como a necessidade de altos impostos, fraude, consequências morais -, o que permitiria capturar o real apoio à redistribuição. Contudo, não há na base principal usada neste trabalho questões dessa natureza para todos os países e para todo o período considerado.

Outra opção consistiria em inferir a postura redistributiva individual a partir de perguntas relacionadas com o espectro político, assumindo que pessoas de direita são menos favoráveis a redistribuir do que pessoas de esquerda, estratégia adotada por Alesina e Angeletos (2005), porém também essa variável poderia trazer um problema adicional se não refletisse a verdadeira postura ideológica das pessoas. Há razões para crer que o cidadão latino-americano não distingue com clareza os conceitos de esquerda e direita, e seus desdobramentos e implicações em políticas (Silva e Figueiredo, 2013). A variável também é uma possível fonte de endogeneidade, pois o grau de apoio a políticas redistributivas pode depender da orientação política e vice-versa. A qualidade das respostas dessa variável na base usada não é boa - por exemplo, é alta a porcentagem de informações faltantes (aproximadamente $15 \%$ ). ${ }^{6}$

Observa-se, na Tabela 2, que a maioria dos entrevistados opina que a distribuição de renda dos seus respectivos países é injusta. No início da década de 2000, a população com percepção negativa da distribuição de renda era aproximadamente $90 \%$. Nos períodos mais recentes, observa-se uma diminuição na porcentagem de pessoas com avaliação negativa da distribuição de renda. Este fato pode refletir que a redução da desigualdade que ocorreu no período foi efetivamente notada pela população. Adicionalmente, a incorporação explícita de redução

Tabela 2

Respostas à Pergunta: "Quão Justa é a Distribuição de Renda no País”, Considerando Respondentes de Todos os Países da Amostra

\begin{tabular}{lccccccccc}
\multicolumn{1}{c}{ Ano } & & & & & & & \\
\hline Resposta & $\mathbf{1 9 9 7}$ & $\mathbf{2 0 0 1}$ & $\mathbf{2 0 0 2}$ & $\mathbf{2 0 0 7}$ & $\mathbf{2 0 0 9}$ & $\mathbf{2 0 1 0}$ & $\mathbf{2 0 1 1}$ & $\mathbf{2 0 1 3}$ & $\mathbf{2 0 1 5}$ \\
\hline Muito justa & $5 \%$ & $2 \%$ & $2 \%$ & $4 \%$ & $2 \%$ & $3 \%$ & $2 \%$ & $3 \%$ & $2 \%$ \\
Justa & $14 \%$ & $9 \%$ & $11 \%$ & $18 \%$ & $19 \%$ & $19 \%$ & $18 \%$ & $24 \%$ & $23 \%$ \\
Injusta & $52 \%$ & $52 \%$ & $54 \%$ & $50 \%$ & $54 \%$ & $53 \%$ & $55 \%$ & $48 \%$ & $49 \%$ \\
Muito injusta & $29 \%$ & $37 \%$ & $33 \%$ & $28 \%$ & $25 \%$ & $25 \%$ & $25 \%$ & $25 \%$ & $26 \%$ \\
\hline
\end{tabular}

Fonte: Latinobarômetro, 1997, 2001, 2002, 2007, 2009, 2010, 2011, 2013, 2015. Elaboração própria. 
Desigualdade de Renda e Demanda por Redistribuição Caminham Juntas...

da desigualdade nas agendas políticas e sociais de alguns países latino-americanos poderia ter feito com que o tema fosse levado em conta pela população.

Na Figura 1, apresenta-se a distribuição das respostas dos dados empilhados por país. Como países cujos habitantes têm a percepção de viverem numa sociedade muito injusta, destacam-se: Argentina, Colômbia, Argentina e Chile. Por outro lado, no Brasil, conhecido por sua alta desigualdade, só $30 \%$ dos entrevistados consideram que moram num país muito injusto. Os habitantes de Costa Rica e Uruguai, países com desigualdade relativamente baixa, são os que manifestam menos insatisfação com a distribuição de renda.

Na Figura 2 observa-se uma relação positiva entre o nível de desigualdade observada (índice de Gini, no eixo horizontal) e a disposição de apoio à redistribuição, expressa pelas respostas à variável mencionada há pouco (no eixo vertical).

\section{Variáveis Individuais}

Forma incluídas as seguintes variáveis individuais:

- Idade em anos e sua versão quadrática.

- Estado conjugal, em duas categorias: "Solteiro" e "Casado". No primeiro grupo, solteiros, separados, divorciados ou viúvos. No segundo, todos aqueles que moram com um companheiro. Os solteiros constituem a referência neste trabalho.

- Homem como variável dummy.

Figura 1

Apoio à Redistribuição: Dados Empilhados 1997-2015, por País

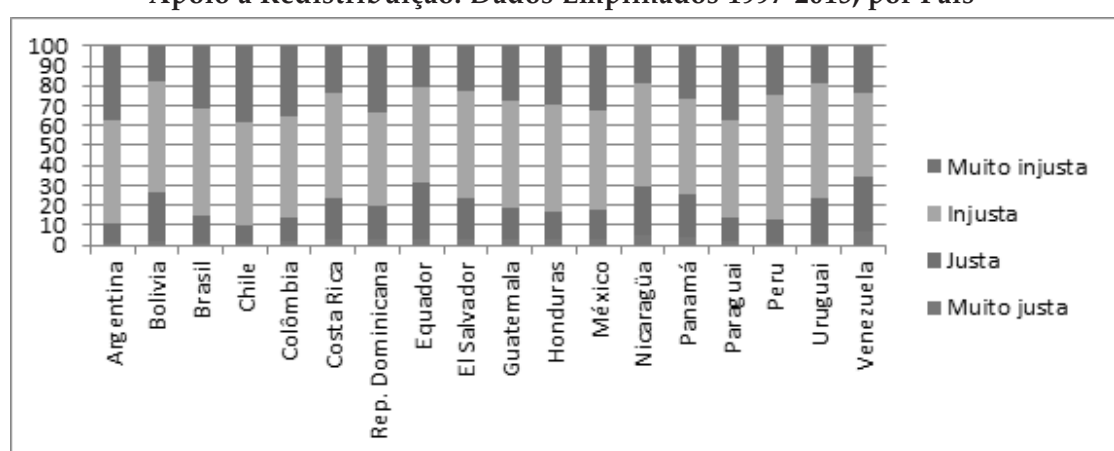

Fonte: Latinobarômetro 1997, 2001, 2002, 2007, 2009, 2010, 2011, 2013, 2015. Elaboração Própria.

DADOS - Revista de Ciências Sociais, Rio de Janeiro, vol. 61, nº 4, 2018 
Figura 2

Apoio à Redistribuição por Coeficiente de Gini

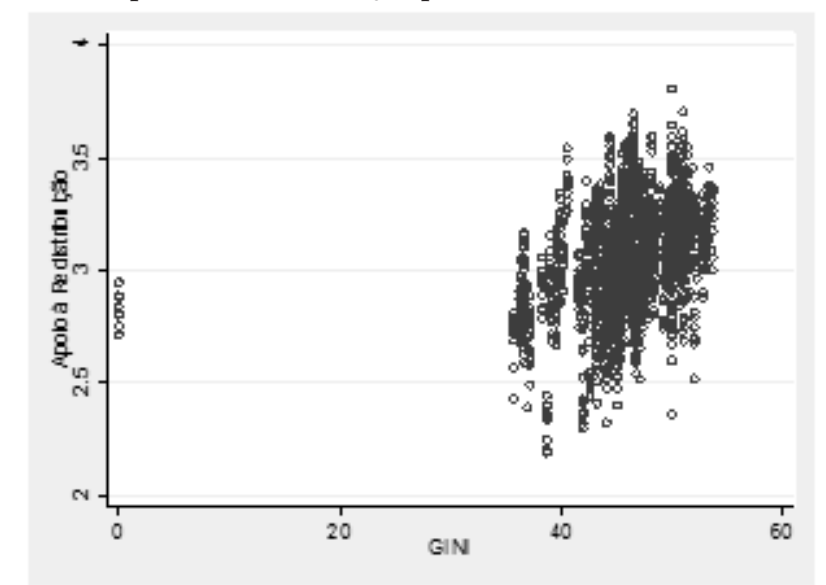

Fonte: Latinobarômetro 1997, 2001, 2002, 2007, 2009, 2010, 2011, 2013, 2015. SWIID. Elaboração Própria.

- Educação como variável dummy, com categorias "Superior" e "Não ensino superior". O primeiro grupo abarca pessoas com ensino superior completo, tanto no nível de graduação, como de pós-graduação. O outro grupo, que é a referência, compõe-se de pessoas com outros níveis de educação e analfabetos.

- Emprego declina-se nas categorias: "Trabalha", "Não trabalha" e "Não pertence à força laboral". Na última categoria estão aposentados, estudantes e donas-de-casa.

- Riqueza. Como já afirmado, o Latinobarômetro não indaga diretamente a renda individual dos entrevistados, porém é possível obter proxies desta variável a partir de outras questões. Seguindo a metodologia de Filmer e Pritchett (2001), também utilizada em estudos de preferências por redistribuição (Cramer e Kaufman, 2011; Gaviria, 2007), obteve-se um índice de bens a partir das informações dos bens duráveis disponíveis no lar dos entrevistados e das características do domicílio. Realizou-se uma análise de componentes principais que permitiu obter o peso de cada variável e, finalmente, obteve-se um índice agregado. ${ }^{7}$ Como os dados analisados pertencem ao período 1997-2015, os bens que aparecem em cada rodada variam conforme a época. Com os resultados do índice os indivíduos foram alocados em: pobres, vulneráveis (categoria mais próxima da "nova classe média"), classe média e ricos. Não existe consenso na literatura sobre os grupos que conformam a classe média, razão pela qual o critério 
Desigualdade de Renda e Demanda por Redistribuição Caminham Juntas...

usado foi o de os alocar em proporções iguais às classes pobre, vulnerável e média observadas na região em cada ano de análise, a exemplo de Ferreira et alli (2013) e CEPAL (2016).

- Religião como variável dummy: "Religiosos" e "Não religiosos". No primeiro grupo estão todos aqueles que manifestaram ser de alguma religião - católico, evangélico, batista, metodista, pentecostal, adventista, testemunhas de Jeová, mórmon, judeus, protestante, umbanda, acredita em Deus, mas não pertence à igreja, kardecista, cristão, espírita, outras. O grupo complementar contempla os que se identificam como agnósticos ou ateus. ${ }^{8}$

Estatísticas descritivas das variáveis individuais de cada ano constam no Apêndice D. Algumas variáveis individuais que se encontram na literatura e que parecem influenciar nas preferências por redistribuição não foram incluídas neste estudo, pois não estão disponíveis em todas as rodadas do Latinobarometro aqui analisadas. Por exemplo: cor/raça, proxies de mobilidade social, o papel da sorte e do esforço como determinantes do sucesso, e a aversão ao risco.

\section{Variáveis Agregadas}

Como medida de desigualdade, variável importante na literatura desde a publicação do pioneiro estudo de Meltzer e Richard (1981), incluiu-se o coeficiente de Gini, obtido na base SWIID.

O PIB per capita (a preços constantes de 2011 e na forma de logaritmo) foi incluído como uma forma de mensurar a riqueza do país. O efeito dessa variável é negativo em estudos para a Europa, como Olivera (2014) e Pittau, Massari e Zelli (2012). Além do nível de riqueza por habitante, foi incluída no estudo também sua taxa de crescimento anual (PIBC). Cramer e Kaufman (2011) sugerem um efeito negativo desta variável para países da América Latina.

Nas Figuras 3, 4 e 5 mostra-se a relação entre desigualdade, crescimento e riqueza no ano de 2015. A Figura 3 mostra a relação incondicional entre apoio à redistribuição e: (i) desigualdade (positiva), (ii) riqueza (negativa), e (iii) crescimento (positiva). Essas relações, alinhadas com a literatura, serão postas à prova com as regressões estimadas por modelos multinível híbridos aplicados ao pseudopainel.

DADOS - Revista de Ciências Sociais, Rio de Janeiro, vol. 61, nº 4, 2018 
Figura 3

Relação entre Desigualdade e Demanda por Redistribuição - 2015

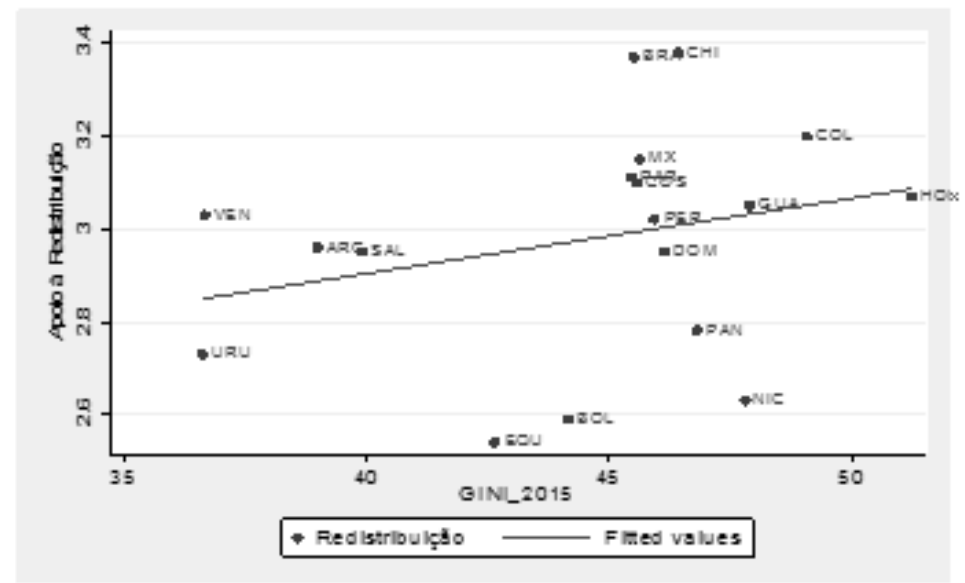

Fontes: SWIID, Latinobarômetro, 2015. Elaboração própria.

Figura 4

Relação entre Crescimento e Demanda por Redistribuição - 2015

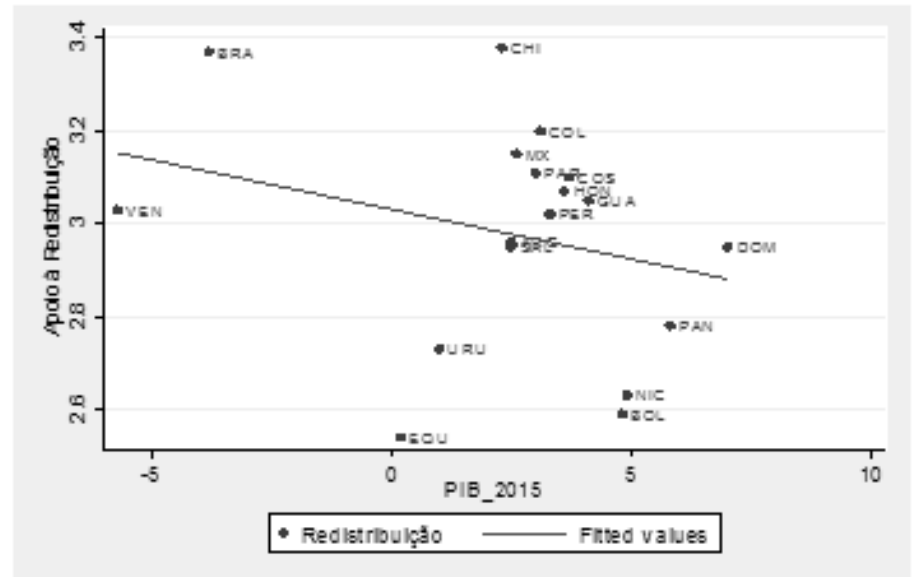

Fonte: BM, Latinobarômetro, 2015. Elaboração própria.

\section{RESULTADOS: APRESENTAÇÃO E DISCUSSÃO}

A Tabela 3 contém os resultados da estimação do pseudopainel. O Modelo 0 contém estimações do modelo nulo. O Modelo 1 mostra as estimações das variáveis individuais. Os Modelos 2, 3 e 4 constituem as estimações híbridas e incluem as variáveis relacionadas com desigualdade, crescimento e riqueza mensuradas com efeitos intra e 
Desigualdade de Renda e Demanda por Redistribuição Caminham Juntas...

Figura 5

Relação entre Riqueza e Demanda por Redistribuição - 2015

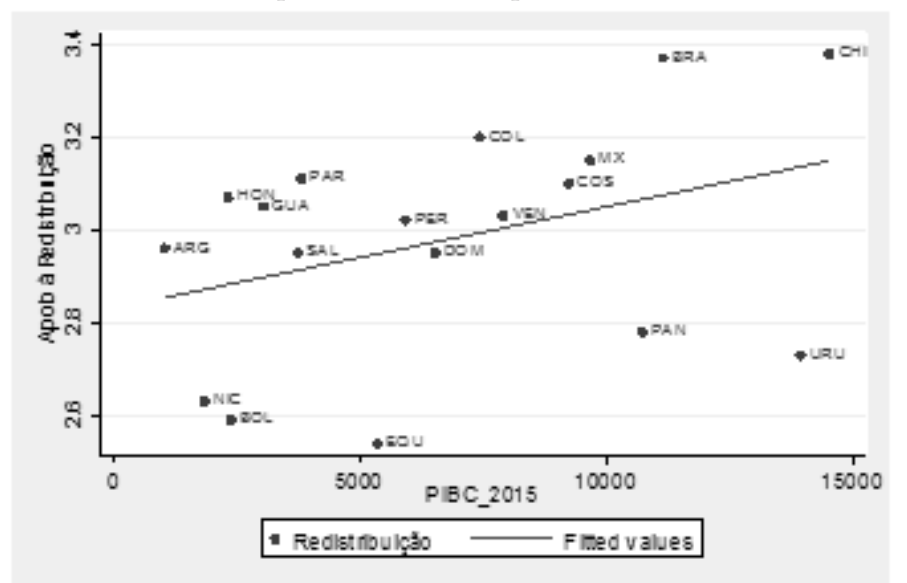

Fonte: BM, Latinobarômetro, 2015. Elaboração própria.

interpaíses. Os modelos 3 e 4 são os de maior interesse, pois contêm informações sobre desigualdade de renda.

No Modelo 0 os coeficientes de correlação intraclasse ao nivel de país e país-ano são: 0,089 e 0,179, ${ }^{9}$ respectivamente, o que significa que a maior parte da variância é explicada pelas diferenças entre países e pela variação temporal, fato esperado devido ao que se analisara na Tabela 3. Já a variação individual representa 0,179.

Tabela 3

Modelos de Apoio à Redistribuição - Pseudopainel

\begin{tabular}{|c|c|c|c|c|}
\hline Variável & M1 & M2 & M3 & M4 \\
\hline \multirow[t]{2}{*}{ Idade } & & $0,0111^{* * *}$ & $0,0113^{* * *}$ & $0,0100^{* * *}$ \\
\hline & & $(0,0029)$ & $(0,0029)$ & $(0,0027)$ \\
\hline \multirow[t]{2}{*}{ Idade $^{2}$} & & $-0,0001^{* * *}$ & $-0,0001^{* * *}$ & $-0,0001^{* * *}$ \\
\hline & & $(0,0000)$ & $(0,0000)$ & $(0,0000)$ \\
\hline \multirow[t]{2}{*}{ Religioso } & & $-0,1691^{* *}$ & $-0,1657^{* *}$ & $-0,2113^{* * *}$ \\
\hline & & $(0,0716)$ & $(0,0712)$ & $(0,0684)$ \\
\hline \multirow[t]{2}{*}{ Homem } & & $-0,0285^{*}$ & $-0,0260^{*}$ & $-0,0346^{* *}$ \\
\hline & & $(0,0156)$ & $(0,0155)$ & $(0,0148)$ \\
\hline \multirow[t]{2}{*}{ Casado } & & $-0,0186$ & $-0,0181$ & $-0,0049$ \\
\hline & & $(0,0338)$ & $(0,0336)$ & $(0,0321)$ \\
\hline
\end{tabular}

(continua)

DADOS - Revista de Ciências Sociais, Rio de Janeiro, vol. 61, no 4, 2018 
Yasmín Salazar Méndez e Fábio Domingues Waltenberg

Tabela 3

Modelos de Apoio à Redistribuição - Pseudopainel (continuação)

\begin{tabular}{|c|c|c|c|c|}
\hline Variável & M1 & M2 & M3 & M4 \\
\hline \multirow[t]{2}{*}{ Empregado } & & $-0,0258$ & $-0,0309$ & $-0,0007$ \\
\hline & & $(0,0382)$ & $(0,0379)$ & $(0,0364)$ \\
\hline \multirow{2}{*}{\multicolumn{2}{|c|}{ Desempregado }} & $0,4709^{* * *}$ & $0,4365^{* * *}$ & $0,2950^{* * *}$ \\
\hline & & $(0,0976)$ & $(0,0973)$ & $(0,0938)$ \\
\hline \multirow[t]{2}{*}{ Superior } & & 0,1193 & 0,1209 & 0,0209 \\
\hline & & $(0,0804)$ & $(0,0799)$ & $(0,0768)$ \\
\hline \multirow[t]{2}{*}{ Pobre } & & $0,3925^{* * *}$ & $0,3901^{* * *}$ & $0,4398^{* * *}$ \\
\hline & & $(0,0744)$ & $(0,0739)$ & $(0,0709)$ \\
\hline \multirow[t]{2}{*}{ Vulnerável } & & 0,0125 & 0,0147 & $0,1428^{*}$ \\
\hline & & $(0,0777)$ & $(0,0772)$ & $(0,0745)$ \\
\hline \multirow[t]{2}{*}{ Média } & & 0,1278 & 0,1372 & $0,2451^{* * *}$ \\
\hline & & $(0,0907)$ & $(0,0902)$ & $(0,0869)$ \\
\hline \multirow[t]{2}{*}{ GINI_inter } & & & $0,0184^{*}$ & $0,0227^{* *}$ \\
\hline & & & $(0,0101)$ & $(0,0107)$ \\
\hline \multirow[t]{2}{*}{ GINI_intra } & & & $0,0051^{* * *}$ & $0,0060^{* * *}$ \\
\hline & & & $(0,0011)$ & $(0,0011)$ \\
\hline \multirow[t]{2}{*}{ PIB_inter } & & & & $0,1011^{* *}$ \\
\hline & & & & $(0,0411)$ \\
\hline \multirow[t]{2}{*}{ PIB_intra } & & & & $0,0229^{* * *}$ \\
\hline & & & & $(0,0079)$ \\
\hline \multirow[t]{2}{*}{ PIBC_inter } & & & & $-0,0019$ \\
\hline & & & & $(0,0277)$ \\
\hline \multirow[t]{2}{*}{ PIBC_intra } & & & & $-0,0179^{* * *}$ \\
\hline & & & & $(0,0014)$ \\
\hline \multirow[t]{2}{*}{ Ano 2001} & & $0,1902^{* * *}$ & $0,1918^{* * *}$ & $0,1081^{* * *}$ \\
\hline & & $(0,0187)$ & $(0,0185)$ & $(0,0191)$ \\
\hline \multirow[t]{2}{*}{ Ano 2002} & & $0,1146^{* * *}$ & $0,1164^{* * *}$ & 0,0157 \\
\hline & & $(0,0193)$ & $(0,0192)$ & $(0,0201)$ \\
\hline \multirow[t]{2}{*}{ Ano 2007} & & $-0,0325^{*}$ & $-0,0232$ & $-0,0266$ \\
\hline & & $(0,0197)$ & $(0,0197)$ & $(0,0194)$ \\
\hline \multirow[t]{2}{*}{ Ano 2009} & & $-0,0372^{*}$ & $-0,0206$ & $-0,1454^{* * *}$ \\
\hline & & $(0,0192)$ & $(0,0195)$ & $(0,0213)$ \\
\hline \multirow[t]{2}{*}{ Ano 2010} & & $-0,0314^{*}$ & $-0,0006$ & $-0,0151$ \\
\hline & & $(0,0187)$ & $(0,0198)$ & $(0,0193)$ \\
\hline
\end{tabular}


Desigualdade de Renda e Demanda por Redistribuição Caminham Juntas...

Tabela 3

Modelos de Apoio à Redistribuição - Pseudopainel (continuação)

\begin{tabular}{lllll}
\hline Variável & M1 & M2 & M3 & M4 \\
\hline Ano 2011 & & $-0,0177$ & 0,0030 & $-0,0317$ \\
& & $(0,0208)$ & $(0,0212)$ & $(0,0212)$ \\
Ano 2013 & & $-0,0573^{* * *}$ & $-0,0349$ & $-0,0808^{* * *}$ \\
& & $(0,0208)$ & $(0,0213)$ & $(0,0213)$ \\
Ano 2015 & & $-0,0265$ & $-0,0016$ & $-0,0780^{* * *}$ \\
& & $(0,0202)$ & $(0,0209)$ & $(0,0214)$ \\
Constante & $3.0499^{* * *}$ & $2.7643^{* * *}$ & $1.8985^{* * *}$ & 0.8763 \\
& $(0,0481)$ & $(0,1049)$ & $(0,4689)$ & $(0,5908)$ \\
Variância & & & & \\
País & $0,0214^{* * *}$ & $0,0247^{* * *}$ &, $0206^{* * *}$ & $0,0145^{* * *}$ \\
País-Ano & $0,0099^{* * *}$ & $0,0000^{* * *}$ & $0,0000^{* * *}$ & $0,0000^{* * *}$ \\
Indivíduos &, $0255^{* * *}$ & $0,0236^{* * *}$ & $0,0234^{*}$ &, $0212^{* * *}$ \\
N(País) & 18 & 18 & 18 & 18 \\
N(Anos) & 10 & 10 & 10 & 10 \\
N(Indivíduos) & 1809 & 1809 & 1809 & 1809 \\
AIC & $-1090,456$ & $-1263,893$ & $-1286,357$ & $-1439,046$ \\
BIC & $-1062,953$ & $-1131,88$ & $-1148,844$ & $-1274,03$ \\
\hline
\end{tabular}

Fonte: Latinobarômetro, 1997, 2001, 2002, 2007, 2009, 2010, 2011, 2013, 2015; SWIID, Banco Mundial. Elaboração própria.

Desvio padrão entre parênteses ${ }^{*} \mathrm{p}<0,10,{ }^{* *} \mathrm{p}<0,05,{ }^{* * *} \mathrm{p}<0,01$.

\section{Desigualdade de Renda e Demanda por Redistribuição \\ Caminham Juntas na América Latina no Período 1997-2015}

Nos modelos 3 e 4, as medidas da desigualdade inter e intra são significativas e positivas em todas as especificações, inclusive depois da inclusão das variáveis de crescimento e riqueza (modelo 4). Isto sugere que a probabilidade de apoio a políticas redistributivas é maior nos países com maior desigualdade, e em momentos de maior desigualdade. O efeito significativo do coeficiente de Gini sugere que, ante um incremento na desigualdade, os cidadãos exigiriam mais dos governos, no tempo, de modo que há evidência do cumprimento da previsão do modelo MR.

Este resultado indica que, quando tomados em conjunto, latino-americanos teriam uma atitude frente à desigualdade de renda mais similar à de europeus que de estadunidenses, e o paradoxo da redistribuição não valeria nessa região.

DADOS - Revista de Ciências Sociais, Rio de Janeiro, vol. 61, nº 4, 2018 
O efeito positivo da desigualdade sugere que, ante os altos níveis de desigualdade nos anos 1990, os latino-americanos podem ter exigido dos governos alguma forma de redistribuição, originando a movimentação positiva em prol de mais igualdade já comentada. Gaviria (2007:30) também observara alto apoio à redistribuição na América Latina, bem como um aumento no gasto social, e referiu-se a estes fatos como a "materialização política" dos pedidos da população. Mais tarde, observou-se tendência de queda na desigualdade na maioria dos países (Cornia, 2013). Birdsall (2012) sustenta que, apesar da coincidência política com a eleição de muitos governos de esquerda, a transformação se deu em todos os regimes políticos, ainda que nos países de regime social-democrata e de esquerda, tenha havido mais avanços, seguidos por países governados por coalizões de centro, como a Costa Rica, e então nos governados pela centro-direita.

Neste sentido, as Figuras 6 e 7 revelam que os países reivindicantes de mais justiça social seriam a Argentina, o Paraguai e o Chile, enquanto Bolívia e Equador, apesar de governados por coalizações claramente de esquerda, apoiariam menos. Em que pesem diferenças no nível de apoio à redistribuição nos diferentes países da região, elas são pequenas, o que poderia ser interpretado como uma onda geral em prol de mais justiça social. Por exemplo, na Figura 6 observa-se que a Argentina mostra uma tendência de apoio à redistribuição positiva $(0,3)$, po-

Figura 6

Interceptos Aleatórios por País

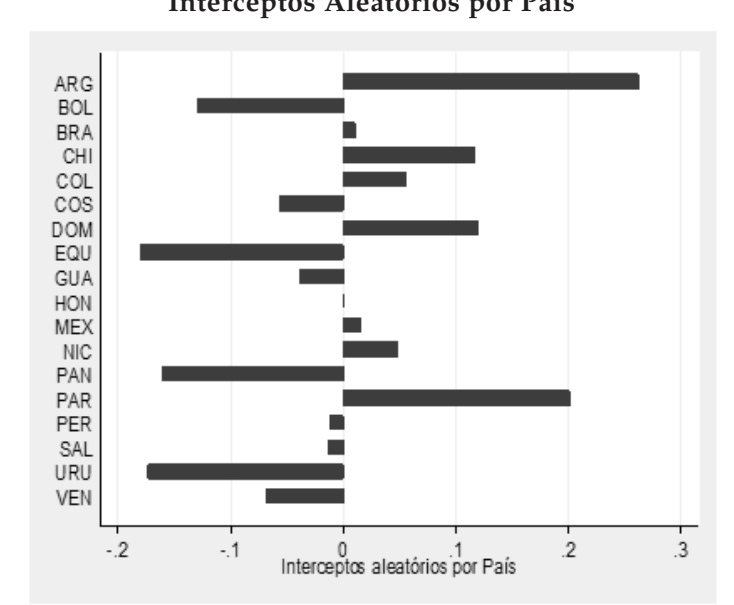

Fonte: Latinobarômetro, 1997, 2001, 2002, 2007, 2009, 2010, 2011, 2013, 2015; SWIID, Banco Mundial. Elaboração própria. 
Desigualdade de Renda e Demanda por Redistribuição Caminham Juntas...

Figura 7

Apoio Predito a Redistribuição por Nível de Desigualdade

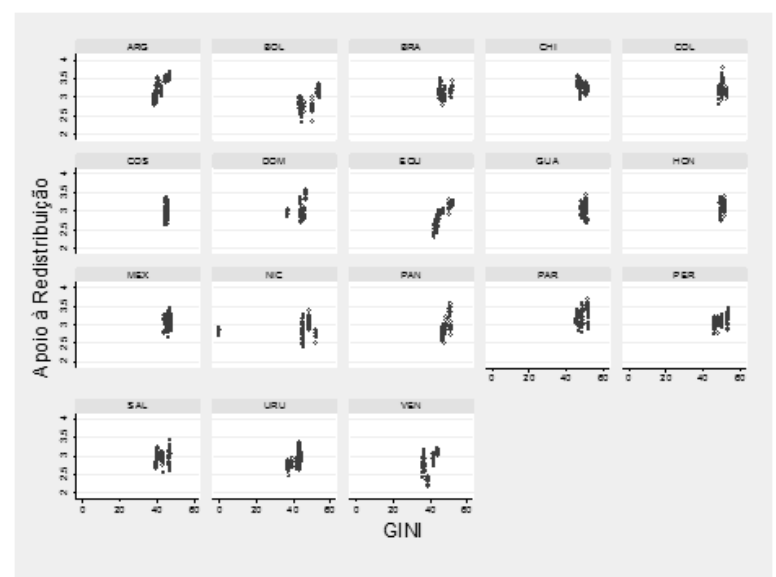

Fonte: Latinobarômetro, 1997, 2001, 2002, 2007, 2009, 2010, 2011, 2013, 2015; SWIID, Banco Mundial. Elaboração própria.

rém, comparada com países com tendência negativa como o Equador e a Bolívia, não há grandes diferenças.

\section{Breve Análise dos Coeficientes das Variáveis Agregadas através dos Modelos}

O nível de riqueza nacional, medida pela variável $P I B$, mostra efeito significativo positivo, tanto entre países quanto no interior dos mesmos. Este resultado confirma outros obtidos anteriormente, por exemplo, por Cramer e Kaufman (2011), que tentam explicá-lo levantando a hipótese de que um maior nível geral de riqueza daria mais acesso a informações, levando a mais demandas por redistribuição. Outros autores entendem que esse tipo de resultado só se observa em países relativamente pobres, como são os da América Latina, visto que, partir de certo patamar de padrão de vida médio, haveria saturação, de forma a que o apoio médio à redistribuição decairia (Haller et alli, 1989). Não temos aqui elementos para aprofundar essas hipóteses.

A variação da riqueza, medida pela variável PIB per capita, por outro lado, é negativa e significativa intrapaíses, mas não entre países, resultado parcialmente semelhante aos de Schmidt (2016), Haggard, Kaufman e Long (2013). Poderia refletir a hipótese de que, em momentos de crescimento da riqueza, a exposição a riscos sociais é relativamente menor em cada país, conduzindo os agentes a se manifestarem 
menos insatisfeitos com o status quo distributivo (Dion e Birchfield, 2010; Cramer e Kaufman, 2011; Jaeger, 2013; e Haggard, Kaufman e Long, 2013).

\section{Breve análise dos coeficientes das variáveis individuais}

No Modelo 4, observa-se que a medida de riqueza individual é significativa e positiva para os pobres e a classe média e, em menor grau, para os vulneráveis - diferentemente do que observam Cramer e Kaufman (2011), que encontraram efeito significativo positivo para a classe média e não significativo para as pobres. $O$ fato de os pobres serem mais favoráveis a redistribuir no tempo que a classe média, conforme se observa neste estudo, pode revelar uma preocupação dos pobres com suas verdadeiras possibilidades de ascender social e economicamente - sem ilusões de que ganhariam um assento no trem da ascensão social em curso na região em parte do período analisado, manifesta sobretudo no crescimento da "nova classe média".

Por outro lado, uma classe vulnerável relativamente acomodada pode significar um sinal de alarme para a região, considerando o potencial papel desse grupo como fonte de pressão e apoio a reformas políticas e institucionais. O efeito pouco significativo desta variável pode refletir um forte desejo de identificação deste grupo com a classe média tradicional e ricos que com dos mais pobres, na linha das hipóteses levantadas por Lupu e Pontusson (2010) e Birdsall (2012). O resultado poderia revelar um conflito de interesses entre os dois grupos menos favorecidos do estudo.

Por fim, o resultado poderia refletir a mudança política em curso na região. Depois do período de redistribuição coincidente com o surgimento de partidos identificados como de esquerda no espectro político, particularmente Argentina, Venezuela e Equador, observa-se movimentação nas forças políticas em direção à direita, como revelam os resultados das últimas eleições na Argentina, o conflito social na Venezuela e a vitória apertada do partido de esquerda no Equador.

A Figura 8 contém as predições marginais de apoio à redistribuição por quintis, mostrando a relação descrita anteriormente.

A idade é significativa e positiva em todos os modelos, com o termo quadrático negativo, indicando uma relação crescente, mas a taxas 
Desigualdade de Renda e Demanda por Redistribuição Caminham Juntas...

Figura 8

Predições Marginais do Apoio à Redistribuição
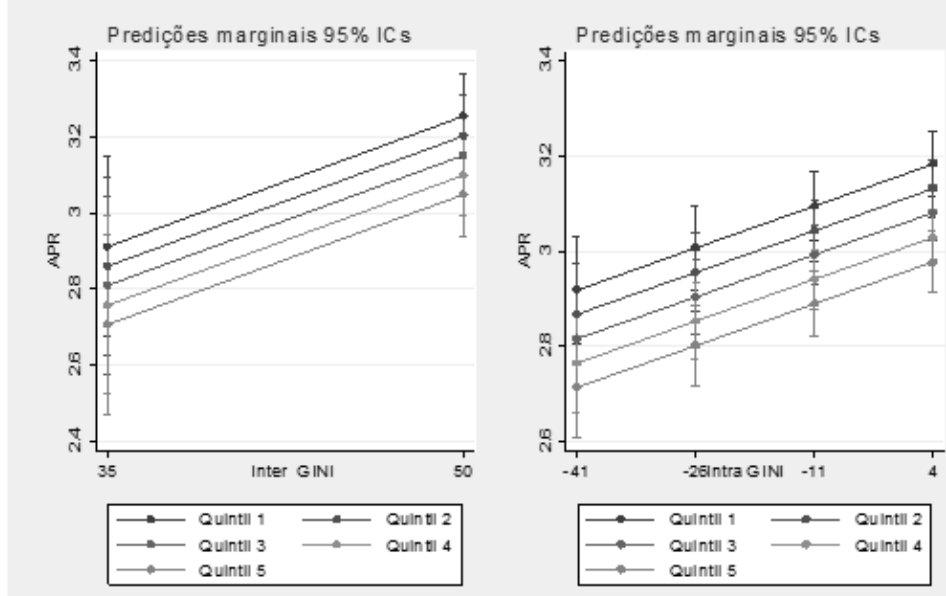

Fonte: Latinobarômetro, 1997, 2001, 2002, 2007, 2009, 2010, 2011, 2013, 2015; SWIID, Banco Mundial Elaboração própria.

cada vez menores. Na literatura, encontram-se resultados divergentes com respeito a esta variável. ${ }^{10}$

Indivíduos religiosos apoiariam menos políticas redistributivas na América Latina, resultado semelhante ao de estudos prévios (Stegmueller, Scheepers e De Jong, 2011). As crenças religiosas constituiriam uma espécie de seguro frente aos riscos, concorrendo, de certa forma, com a intervenção do Estado (Scheve e Stavasage, 2006).

Homens latino-americanos seriam menos favoráveis a redistribuir do que as mulheres, tendência que confirma estudos anteriores (Corneo e Grüner, 2002; Gaviria, 2007; Haggard Kaufman e Long, 2013). As teorias que explicam as diferentes atitudes de cada um dos sexos baseiam-se no tratamento desigual e a precariedade que as mulheres enfrentam em diversas instâncias da vida (Linos e West, 2003).

O estado conjugal parece não influenciar nas preferências por redistribuição, resultado já observado em Silva e Figueiredo (2013) e Gaviria (2007) na América Latina. Nos trabalhos de Alesina e Giuliano (2010), Alesina e La Ferrara (2005) e Linos e West (2003), observa-se efeito negativo do casamento nas atitudes redistributivas, esperado se o casamento é uma espécie de seguro contra riscos (Linos e West, ibidem).

DADOS - Revista de Ciências Sociais, Rio de Janeiro, vol. 61, nº 4, 2018 
Estar desempregado está positivamente correlacionado à demanda por redistribuição, em linha com a literatura (Linos e West, ibidem). Pessoas que não trabalham poderiam ser mais empáticas com as pessoas de baixa renda, além de experimentar uma situação de vulnerabilidade e insegurança financeira (Alesina e La Ferrara, 2005).

Educação superior não afetaria a demanda por redistribuição na América Latina. O papel da educação é ambivalente na literatura, que reporta tanto um efeito positivo (Haggard, Kaufman e Long, 2013; Silva e Figueiredo, 2013), como um efeito negativo (Alesina e Giuliano, 2011). Por outro prisma, a variável pode ser considerada como uma proxy de risco - pessoas com alto nível de educação estão mais capacitadas e menos vulneráveis no mercado de trabalho (Finseraas, 2009).

\section{CONCLUSÕES}

Grande parte da literatura sobre demanda por redistribuição tem focado em Europa e Estados Unidos. Poucos são os trabalhos que tomam a opinião de cidadãos latino-americanos frente à redistribuição como objeto de estudo. É uma lacuna que não deveria existir, vista a importância teórica da desigualdade social nessa literatura, e sua relevância factual na região. O interesse é maior ainda em face das mudanças ocorridas no início do século XXI em muitos países latino-americanos, sobretudo certa queda na desigualdade de renda em paralelo ao crescimento de uma classe remediada, emergindo bem ou mal da pobreza.

O período analisado neste trabalho - que começa em 1997 e termina em 2015 - é relativamente longo e abarca essa época de transformações. Sem uma medida direta de apoio à redistribuição para o amplo espectro geográfico e temporal utilizado, foi preciso recorrer a uma proxy, que expressa manifestações de descontentamento com o status quo distributivo. Tomados em seu conjunto, os latino-americanos não naturalizaram a desigualdade a ponto de não se importarem com ela. Ao contrário, em sua grande maioria consideram-na injusta.

O cruzamento em cada país e ao longo do tempo entre, de um lado, a variável que expressa o grau de descontentamento com o status quo distributivo, e, de outro lado, o nível de desigualdade vigente, indica correlação positiva, corroborando a previsão clássica do modelo MR. Este resultado indica que, quando tomados em conjunto, latino-americanos teriam uma atitude frente à desigualdade de renda mais similar 
Desigualdade de Renda e Demanda por Redistribuição Caminham Juntas...

à de europeus que de estadunidenses, e o paradoxo da redistribuição não valeria aqui.

É importante relembrar que esse resultado é robusto à inclusão de uma grande bateria de controles individuais e de variáveis agregadas, e ao uso de uma técnica de estimação relativamente sofisticada - de resto, duas contribuições deste estudo à literatura.

A insatisfação com a distribuição de renda é mais intensa entre pobres e a classe média, mas não tanto entre os "vulneráveis", categoria mais próxima da "nova classe média". Não temos elementos para determinar claramente o papel do eleitor mediano nas perspectivas de mudanças futuras, uma vez que não sabemos se a "nova classe média" manterá sua ascensão social, ou não. Mas sabemos que esses quase-pobres ou serão de fato ex-pobres? - terão papel fundamental no rumo que as políticas redistributivas tomarão no futuro.

(Recebido para publicação em 31 de outubro de 2015)

(Reapresentado em 26 de abril de 2017)

(Aprovado para publicação em 01 de agosto de 2018) 


\section{NOTAS}

1. Na última década, o coeficiente de Gini regional variou de 0,5256 em 2000 a 0,4976 em 2010 (Cornia, 2013). Gasparini, Cruces e Tornarolli (2011) mostram que tal tendência foi observada em 15 de 18 países pesquisados, à exceção de Honduras e Nicarágua, com um pequeno aumento, e Costa Rica, estável.

2. Ver em Ferreira et alli (2013) informações e definições sobre a nova classe média na América Latina. Kerstenetzky, Uchoa e Silva (2015) abordam de uma perspectiva crítica o conceito de "nova classe média" no Brasil.

3. É importante ressaltar que a maioria de estudos assume a premissa da relação entre renda e preferências por redistribuição. Um número menor de estudos testa a premissa diretamente. Os estudos mencionados neste parágrafo testam diretamente a premissa.

4. Os países são: Argentina, Bolívia, Brasil, Colômbia, Costa Rica, Chile, El Salvador, Equador, Guatemala, Honduras, México, Nicarágua, Panamá, Paraguai, Peru, República Dominicana, Uruguai e Venezuela. A República Dominicana foi incluída na pesquisa a partir de 2004. A partir de 2002, as amostras passaram a garantir representatividade nacional da população de todos os países estudados. Informes metodológicos e técnicos, bem como os questionários, estão disponíveis em: http:/ / www.latinobarometro.org/latContents.jsp.

5. O método de Monte Carlo consiste na geração de dados artificiais a partir dos quais se estimam os parâmetros de um modelo - a média e a variância - com distintos estimadores, os quais são comparados no sentido de determinar aquele com menor viés e maior eficiência (Wooldridge, 2002).

6. Testes feitos com a variável, mas não reportados aqui, resultaram em coeficientes não significativamente diferentes de zero, e não ocasionaram mudanças importantes nos coeficientes das demais variáveis.

7. A pergunta utilizada para a construção do índice faz referência aos bens e ao acesso a serviços básicos que têm cada domicílio, entre os quais: pais têm quarto distinto dos filhos, casa própria, computador, tablet, máquina de lavar roupas, telefone fixo, celular, smartphone, carro, água quente, esgoto, pelo menos uma comida quente por dia etc.

8. Não se optou por realizar uma divisão por denominação, uma vez que o foco principal deste estudo não é estudar as diferenças que podem surgir no apoio à redistribuição entre as diferentes religiões, e porque uma análise deste tipo exige entrar em detalhes específicos sobre as características das religiões nos países de análise, algo fora do escopo deste artigo. A intensidade da vida religiosa não foi incluída neste estudo devido a que a variável não está disponível em todos os anos analisados.

9. Cálculos feitos usando as seguintes fórmulas nos níveis 2 e 3 , respectivamente: $\rho=\sigma_{u o}^{2} / \sigma_{v o}^{2}+\sigma_{u o}^{2}+\sigma_{e}^{2}, \rho=\sigma_{v o}^{2} / \sigma_{v o}^{2}+\sigma_{u o}^{2}+\sigma_{e}^{2}$

10. Pittau, Massari e Zelli (2012) encontram que o apoio a políticas redistributivas diminui com a idade nos Estados Unidos, e o inverso na Europa, e explicam a diferença em razão de distintas percepções do papel das aposentadorias - para os americanos, seriam uma espécie de "transferência especial", à diferença dos europeus, que a considerariam uma ferramenta de redistribuição propriamente. Olivera (2014) e Corneo e Grüner (2002) encontram efeito positivo da idade, ao contrário de Alesina e La Ferrara (2005). Na América Latina, Gaviria (2007) reporta efeito positivo, enquanto em Cramer e Kaufman (2011) a variável não é significativa. 
Desigualdade de Renda e Demanda por Redistribuição Caminham Juntas...

\section{REFERÊNCIAS BIBLIOGRÁFICAS}

ACEMOGLU, Daron; JOHNSON, Simon; ROBINSON, James. (2002), “Reversal of Fortune: Geography and Institutions in the Making Of the Modern World Income Distribution". Quarterly Journal of Economics, vol. 107, pp. 1231-1294.

ALESINA, Alberto; ANGELETOS, George-Marios. (2005), "Fairness and Redistribution". The American Economic Review, vol. 95, no 4, pp. 960-980.

; GIULIANO, Paola. (2011), "Preferences for Redistribution", in J. Benhabib; M. Jackson e A. Bisin (eds.). Handbook of Social Economics, 1A. North Holland: Elsevier, pp. 93-132.

; LA FERRARA, Eliana. (2005), "Preferences for Redistribution in the Land of Opportunities". Journal of Public Economics, vol. 89, pp. 897-931.

ANDREß, Hans-Jürgen; GOLSCH, Katrin; SCHMIDT, Alexander. W. (2013), Applied Panel Data Analysis for Economic and Social Surveys. Berlim, Springer.

ANGRIST, Joshua; PISCHKE, Jörn-Steffen. (2009), Mostly Harmless Econometrics: An Empiricists Companion. Princeton, Princeton University Press.

BALTAGI, Badi. (2005), Econometric Analysis of Panel Data. Chichester, Wiley.

;SONG, Seuck S. (2006), “Unbalanced panel data: A survey”, Statistical Papers, vol. 47, no 4, pp. 493-523.

BÉNABOU, Roland; OK, Efe. (2001), “Social Mobility and the Demand for Redistribution: The POUM Hypothesis". The Quarterly Journal of Economics, vol. 116, no 2, pp 447-487.

BIRDSALL, Nancy. (2012). A Note on the Middle Class in Latin America. Working Paper 303, Washington, D.C.: Center for Global Development.

BREUSCH, Trevor; WARD, Michael; NGUYEN, Hoa; KOMPAS, Tom. (2011a), “FEVD: Just IV or Just Mistaken?" Political Analysis, vol. 19, no.2, pp. 165-169.

(2011b), "On the fixed-effects vector decomposition", Political Analysis, vol. 19, no.2, pp. 123-134.

CAMERON, Colin; GELBACH, Jonah; MILLER, Douglas. (2008), “Bootstrap-Based Improvements for Inference with Clustered Errors". The Review of Economics and Statistics, vol. 90, no 3, pp. 414-427.

CAMERON, Adrian; TRIVEDI, Pravin. (2009), "Microeconometrics with Stata". College Station, TX: StataCorp LP.

CEPAL. (2013), Panorama Social de América Latina 2013.

BREDEMEIER, Christian. (2014), "Imperfect Information and the Meltzer-Richard Hypothesis". Public Choice, vol.159, no 3-4, pp. 561-576.

CORNEO, Giacomo; GRÜNER, Hans. (2002), “Individual Preferences for Political Redistribution". Journal of Public Economics, vol. 83, pp. 83-107.

CRAMER, Brian KAUFMAN, Robert. (2011), "Views of Economic Inequality in Latin America". Comparative Political Studies, vol. 44, no 9, pp. 1206-1237.

DADOS - Revista de Ciências Sociais, Rio de Janeiro, vol. 61, nº 4, 2018 
Yasmín Salazar Méndez e Fábio Domingues Waltenberg

CORNIA, Giovanni. (2013), "Inequality Trends and their Determinants: Latin America over 1990-2010", in A. Cornia (ed.). Falling Inequality in Latin America: Policy Changes and Lessons. Nova York, Oxford University Press.

DALLINGER, Ursula. (2010), “Public support for redistribution: what explains cross-national differences? Journal of European Social Policy, vol. 20, no. 4, pp. 333-349.

DEATON, Angus. (1985), "Panel Data from Times Series of Cross-Sections". Journal of Econometrics, vol. 30, pp. 109-126.

DEVEREUX, Paul. (2007), "Small-Sample Bias in Synthetic Cohort Models of Labor Supply". Journal of Applied Econometrics, vol. 22, no 4, pp. 839-848.

DION, Michelle; BIRCHFIELD, Vicki. (2010), “Economic Development, Income Inequality, and Preferences for Redistribution". International Studies Quarterly, vol. 54, pp. 315-334.

ERVASTI, Heikki. (2012), “Who Hates the Welfare State? Criticism of the Welfare State in Europe", in H. Ervasti; J. Goul; T. Fridberg e K. Ringdal (eds.). The Future of the Welfare State Social Policy. Attitudes and Social Capital in Europe. Cheltenham: Edward Elgar Publishing.

FAIRBROTHER, Malcolm. (2014), “Two Multilevel Modeling Techniques for Analyzing Comparative Longitudinal Survey Datasets". Political Science Research and Methods, vol. 2, pp. 119-140.

(2011). “The application of multilevel models to repeated cross-sectional survey data". Paper to be presented at ECPR, Reykjavik.

FERREIRA, Francisco; MESSINA, Julian; RIGOLINI, Jamele; LÓPEZ-CALVA, LuisFelipe; LUGO, Ana María; VAKIS; Renos. (2013), “Economic Mobility and the Rise of the Latin American Middle Class". World Bank Latin American and Caribbean Studies, no 11858. Washington, D.C., World Bank.

FILMER, Deon; PRITCHETT, Lant. (2001), “Estimating Wealth Effects Without Expenditure Data or Tears: An Application to Education Enrollments in States of India". Demography, vol. 38, no 1, pp. 115-132.

FINSERAAS, Henning. (2009), “Income Inequality and Demand for Redistribution: A Multilevel Analysis of European Public Opinion". Scandinavian Political Studies, vol. 32, no 1, p. 94-119.

GASPARINI, Leonardo; CRUCES, Guillermo; TORNAROLLI, Leopoldo. (2011), “Recent Trends in Income Inequality in Latin America". Economía, vol. 11, no 2, pp. 147-190.

GAVIRIA, Alejandro. (2007), “Social Mobility and Preferences for Redistribution in Latin America". Economía, vol. 8, no 1, pp. 55-96.

GOUVEIA, Miguel; MASIA, Neal. (1998), “Does the Median Voter Model Explain the Size of Government? Evidence from the States". Public Choice, vol. 97, pp. 159-177.

GREENE, William H. (2011), “Econometric Analysis". (International edition), 7o. ed. New York, Pearson Editora.

HAGGARD, Stephan; KAUFMAN, Robert; LONG, James. (2013), “Income, Occupation, and Preferences for Redistribution in the Developing World". Studies in Comparative International Development, vol. 48, pp.113-140. 
Desigualdade de Renda e Demanda por Redistribuição Caminham Juntas...

HALLER, Max; KOLOSI, Támas; RÓBERT, Péter. (1989), “Social Mobility in Austria, Czechoslovakia, and Hungary: An Investigation of the Effects of Industrialization, Socialist Revolution, and National Uniqueness". International Journal of Sociology, vol. 19, no 4, pp. 3-47.

HSIAO, Cheng. (1986), Analysis of Panel Data. Cambridge, Cambridge University Press.

JAEGER, Mads. (2013), "The Effect of Macroeconomic and Social Conditions on the Demand for Redistribution: A Pseudo Panel Approach". Journal of European Social Policy, vol. 23, no 2, pp. 149-163.

KARABARBOUNIS, Loukas. (2011), “One Dollar, One Vote”. The Economic Journal, vol. 121, pp. 621-649.

KENWORTHY, Lane; McCALL, Leslie. (2008), “Inequality, Public Opinion, and Redistribution". Socio-Economic Review, vol. 6, no 1, pp. 35-68.

KERSTENETZKY, Celia; UCHOA, Christiane; SILVA, Nelson. (2015), “The Elusive New Middle Class in Brazil”. Brazilian Political Science Review, vol. 9, no 3, pp. 21-41.

LINOS, Katerina; WEST, Martin. (2003), "Self-interest, Social Beliefs, and Attitudes to Redistribution: Re-addressing the Issue of Cross-National Variation". European Sociological Review, vol. 19, no 4, pp. 393-409. 2003.

LUPU, Noam; PONTUSSON, Jonas. (2011), “The Structure of Inequality and the Politics of Redistribution". American Political Science Review, vol. 105, no 2, pp. 316-336.

MAAS, Cora; HOX, Joop J. (2005), "Sufficient sample sizes for multilevel modelling". Methodology, vol. 1, no. 3, pp. 86-92.

MCCARTY, Nolan; PONTUSSON, Jonas. (2009), "The Political Economy of Inequality and Redistribution", in W. Salverda; B. Nolan e T. Smeeding (eds.), The Oxford Handbook of Economic Inequality. Oxford, Oxford University Press, pp. 665-692.

MELTZER, Allan; RICHARD, Scott. (1981), “A Rational Theory of the Size of Government". Journal of Political Economy, vol. 89, pp. 914-927.

MILANOVIC, Branko. (2000), “The Median Voter Hypothesis, Income Inequality and Income Redistribution: An Empirical Test with the Required Data". European Journal of Political Economy, vol. 16, no 3, pp. 367-410.

(2010), "Four Critiques of the Redistribution Hypothesis: An Assessment". European Journal of Political Economy, vol. 26, pp. 147-154.

MOENE, Karl; WALLERSTEIN, Michael. (2003), “Earnings Inequality and Welfare Spending: A Disaggregated Analysis". World Politics, vol. 55, pp. 485-516.

MÖHRING, Katja. (2012), “The fixed-effects as an alternative to multilevel analysis for cross-national analyses. GK Soclife, Working Papers Series, no. 16.

MONTGOMERY, Mark; GRAGNOLATI, Michelle; BURKE, Kathlenn; PAREDES, Edmundo. (2000), "Measuring Living Standards with Proxy Variables". Demography, vol. 27, pp. 155-174.

MOULTON, Brent. (1986), "Random Group Effects and the Precision of Regression Estimates". Journal of Econometrics, vol. 32, pp. 385-397.

OLIVERA, Javier. (2014), "Preferences for Redistribution After the Economic Crisis". Economics and Business Letters, vol. 3, no 3, pp. 137-145.

DADOS - Revista de Ciências Sociais, Rio de Janeiro, vol. 61, nº 4, 2018 
Yasmín Salazar Méndez e Fábio Domingues Waltenberg

PERSSSON, Torsten; TABELLINI, Guido. (2004), "Constitutional Rules and Economic Policy Outcomes". American Economic Review, vol. 94, pp. 25-46.

PERSSSON, Torsten; TABELLINI, Guido. (1994), "Is Inequality Harmful for Growth?" The American Economic Review, vol. 84, no. 3, pp. 600-621.

PIKETTY, Thomas. (1995), "Social Mobility and Redistributive Politics". The Quartely Journal of Economics, vol. 110, no 3, pp. 551-584.

PITTAU, Maria; MASSARI, Riccardo; ZELLI, Roberto. (2012), “Hierarchical Modelling of Disparities in Preferences for Redistribution". Oxford Bulletin of Economics and Statistics, vol. 75, no 4, pp. 556-584.

PLÜMPER, Thomas; TROEGER, Vera E. (2007), “Efficient Estimation of Time-Invariant and Rarely Changing Variables in Finite Sample Panel Analyses with Unit Fixed Effects". Political Analysis, vol. 15, no. 2, pp. 124-139.

. (2011), "Fixed Effects Vector Decomposition: Reply". Disponível em: https://papers.ssrn.com/sol3/papers.cfm?abstract_id=1737480. Acesso em: 26 dez 2018.

PRITCHETT, Lant. (2001), “Where Has All the Education Gone?". World Bank Economic Review, vol. 15, pp. 367-391.

RYDER, Norman B. (1965), "The cohort as a concept in the study of social change". American Sociological Review, vol. 30, no. 6, pp. 843-861.

SCHEVE, Kenneth; STASAVAGE, David. (2006), "Religion and Preferences for Social Insurance". Quarterly Journal of Political Science, vol. 1, pp. 255-286.

SCHMIDT-CATRAN, Alexander. (2016), “Economic Inequality and Public Demand for Redistribution: Combining Cross-sectional and Longitudinal Evidence". Socio-Economic Review, vol. 14, no 1, pp. 119-140.

SEFTON, Tom. (2005), “Give and Take: Attitudes to Redistribution”, in A Park, J Curtice, K Thomson, C Bromley, M Phillips, M Johnson (eds.), British Social Attitudes 22nd Report. London, Sage Publications, pp. 1-32.SILVA, Cleiton. e FIGUEIREDO, Erik. (2013), “Movilidad Social y Demanda de Redistribución del Ingreso en América Latina". Revista de la CEPAL, vol. 110, pp. 69-84.

SOLT, Frederick. (2009), "Standardizing the World Income Inequality Database". Social Science Quarterly, vol. 90, no 2, pp. 231-242.

Standardized World Income Inequality Database (SWIID), (2011), Version 3.1, dezembro.

STEGMUELLER, Danie.; SCHEEPERS, Peer; ROßTEUTSCHER, Sigrid; DE JONG, Eelke. (2011), "Support for Redistribution in Western Europe. Assessing the Role of Religion". European Sociological Review, vol. 16, pp. 1-16.

STIGLER, George. (1970), “Director's Law of Public Income Redistribution". Journal of Law and Economics, vol. 13, pp. 1-10.

TÓTH, István; KELLER, Tamás. (2011), “Income Distributions, Inequality Perceptions and Redistributive Claims in European Societies". Amsterdam, AIAS, Gini Discussion Paper Number 7.

TULLOCK, Gordon. “Comment”. (1983), Public Choice, vol. 41, pp. 819-822. 
Desigualdade de Renda e Demanda por Redistribuição Caminham Juntas...

VERBEEK, Marno. (2008), "Pseudo Panels and Repeated Cross-Sections", in L. Matyas e P. Sevestre (eds.), The Econometrics of Panel Data: Fundamentals and Recent Developments in Theory and Practice. Berlim, Springer, pp. 369-383.

_ _ NIJMAN, Theo. (1992), "Can Cohort Data Be Treated as Genuine Panel Data?". Empirical Economics, vol. 17, no 9, pp. 9-23.

WORLD BANK. (2014), The World Development Indicators.

WOOLDRIDGE, Jeffrey. (2002), "Econometric Analysis of Cross Section and Panel Data". Cambridge, MA, The MIT Press. 
Desigualdade de Renda e Demanda por Redistribuição Caminham Juntas...

RESUMO

Desigualdade de Renda e Demanda por Redistribuição Caminham Juntas na América Latina no Período 1997-2015

Por que em alguns países há mais redistribuição de renda do que em outros? A questão é relevante, não apenas para o desenho de sistemas de tributação e de políticas redistributivas, mas também para uma melhor compreensão do surgimento de conflitos sociais ou da posição (in)tolerante dos habitantes de um país frente a situações de desigualdade social. A literatura, centrada em estudos para países desenvolvidos, aponta que as chamadas "preferências por redistribuição" dependem de inúmeros fatores, tanto de ordem macro como microeconômica. Neste trabalho se combinam dados de três fontes distintas para se estimar um modelo multinível com dados empilhados e um pseudopainel, a fim de se analisar o efeito da desigualdade de renda na demanda por redistribuição na América Latina. Os resultados revelam que a probabilidade de apoio a políticas redistributivas aumenta em países/momentos com desigualdade mais elevada, e também indicam que os pobres estariam demandando sociedades mais igualitárias.

Palavras-chave: demanda por redistribuição, desigualdade, modelo multinível, pseudopainel, América Latina

\section{ABSTRACT}

Income inequality and demand for redistribution in Latin America, from 1997-2015

Why in some countries is there more redistribution of income than in others? The issue is relevant, not only for the design of taxation systems and redistributive policies, but also for a better understanding of the emergence of social conflicts or the general tolerance of the population to situations of social inequality. The literature, centered on studies of developed countries, points out that the so-called "preferences for redistribution" depend on numerous factors, both macro and microeconomic. In this article, data from three different sources are combined to estimate a multilevel model with stacked data and a pseudo-panel, in order to analyze the effect of income inequality on the demand for redistribution in Latin America. The results show that the probability of support for redistributive policies increases in countries or historical moments marked by higher inequality, and also indicate that the Latin American poor are increasingly demanding more egalitarian societies.

Key words: demand for redistribution, income redistribution, multilevel model, inequality, Latin America

DADOS - Revista de Ciências Sociais, Rio de Janeiro, vol. 61, n 4, 2018 
Yasmín Salazar Méndez e Fábio Domingues Waltenberg

RÉSUMÉ

L'inégalité des revenus et la demande de redistribution Walk en Amérique latine entre 1997 et 2015

Pourquoi la redistribution des revenus dans certains pays c'est plus importante que dans des autres? La question est pertinente, non seulement pour la conception des systèmes de taxation et des politiques de redistribution, mais également pour une meilleure compréhension de l'émergence de conflits sociaux ou de la position (in)tolérante des habitants d'un pays face aux situations d'inégalité sociale. La littérature, centrée sur des études pour les pays développés, souligne que les "préférences de redistribution" dépendent de nombreux facteurs, à la fois macroéconomiques et microéconomiques. Dans ce travail, les données de trois sources différentes sont combinées pour estimer un modèle à plusieurs niveaux avec données superposées et un pseudopainel, afin d'analyser l'effet de l'inégalité des revenus sur la demande de redistribution en Amérique latine. Les résultats montrent que la probabilité de soutien aux politiques de redistribution augmente dans les pays/périodes où l'inégalité est élevée et indique également que les pauvres exigent des sociétés plus égalitaires.

Mots-clés: demande de redistribution, inégalité, modèle multiniveau, pseudopainel, Amérique latine

\section{RESUMEN}

Desigualdad de renta y reivindicación por redistribución caminan juntas en Latinoamérica (1997-2015)

¿Por qué en algunos países hay más redistribución de ingresos que en otros? La cuestión es relevante, no sólo para el diseño de sistemas de tributación y de políticas redistributivas, sino también para una mejor comprensión del surgimiento de conflictos sociales o de la posición de los habitantes de un país frente a situaciones de desigualdad social. La literatura, centrada en casos de países desarrollados, señala que las llamadas 'preferencias por redistribución' dependen de innumerables factores, tanto de orden macro como microeconómico. En este trabajo se combinan datos de tres fuentes distintas para estimar un modelo multinivel con datos apilados y un pseudopainel, a fin de analizar el efecto de la desigualdad de renta en la demanda por redistribución en América Latina. Los resultados revelan que la probabilidad de apoyo a políticas redistributivas aumenta en países/momentos con desigualdad más elevada, y también indican que los pobres estarían demandando sociedades más igualitarias.

Palavras-chave: reivindicación por redistribución; desigualdade; modelo multinivel; pseudopanel; América Latina 